\title{
Role of Character Strengths and Stress in Psychological Symptoms among Chinese Secondary Vocational School Students
}

\author{
Tingting Li, Xiaoming Liu \\ Institute of Psychology, Northeast Normal University, Changchun, China \\ Email: 309550409@qq.com \\ Received 11 December 2015; accepted 16 January 2016; published 19 January 2016 \\ Copyright $(\subset 2016$ by authors and Scientific Research Publishing Inc. \\ This work is licensed under the Creative Commons Attribution International License (CC BY). \\ http://creativecommons.org/licenses/by/4.0/ \\ (c) (i) 0 pen Access
}

\begin{abstract}
Background: Character strengths are important psychology resources, which affect the academic and social development of students at secondary vocational schools. Purpose: We aimed to clarify the relationship between character strengths, psychological stress, and psychological symptoms among these students from a positive psychological perspective. By focusing on virtues and strengths, we suggest improvements to school education and family upbringing. Sample: A total of 282 secondary vocational school students were recruited. Design and Method: Students were asked to complete the Chinese Virtues Questionnaire, Life Stress Rating Scale, and Symptom Checklist-90. Statistical analyses were conducted using SPSS 19.0. Results: Regression analyses indicated that the interaction between relationship strengths and family stress explained $45 \%$ of the variance in psychological symptoms. This study clarified the positive role of character strengths in stressful situations. Thus, helping secondary vocational school students recognize and use their strengths is conducive to improving their health. Conclusion: Our results should also help teachers and parents adopt a strengths perspective, which might encourage students to explore and develop their strengths.
\end{abstract}

\section{Keywords}

Secondary Vocational School Students, Character Strengths, Psychological Stress, Psychological Symptom, Moderation

\section{Introduction}

China strongly advocates for the development of vocational education due to a growing demand for professional

How to cite this paper: Li, T. T., \& Liu, X. M. (2016). Role of Character Strengths and Stress in Psychological Symptoms among Chinese Secondary Vocational School Students. Psychology, 7, 52-61. http://dx.doi.org/10.4236/psych.2016.71007 
and technical personnel. Improving the teaching quality at secondary vocational schools has become an important topic; however, there remains little research focusing on secondary vocational school students' psychological health. Although these students are the same age as high school students, their educational experience makes them face a more complicated situation. Particularly, it is commonly believed that secondary vocational school students are those who failed on high school entrance examination; thus, they have no choice but to attend such a school (rather than it being an optimal choice) or have a learning disability (Wu \& Yao, 2013). These societal perceptions can lead to serious psychological problems. Specifically, secondary vocational school students who are not satisfied with themselves may develop inferiority complexes, low self-evaluations, and low self-efficacy (Zhou \& Li, 2010). It may also affect the development of social relationships, which can exacerbate the aforementioned psychological problems, thereby forming a vicious cycle that generates further negative events. To break this cycle, these students should discover their own internal potential and obtain greater social support. In recent years, some scholars have advanced the notion of positive mental health education, which is based on the fields of positive and developmental psychology. Compared with traditional education, positive education focuses on the positive aspects of humanity and society and emphasizes development and promotion of these positive aspects. This fosters healthy development and trains students' inner potential (Meng, 2008).

Recent topics of interest in positive psychology have been investigating how to help adolescents develop positive personality traits related to school, social life, family, and general development, as well as ways for training educators on how to cultivate optimal development and teach adaptive aspects of human nature. Gillham et al. (2011) and Toner et al. (2012) focused on character strengths and well-being during adolescence, and Duan et al. (2014) focused on life stress and virtues among students. Such studies may assist in the development of potential perspective and positive educational programs for young people. Despite lack of a sound theory for outlining the relationships between character strengths, stress, and psychological symptoms, potential relationships can be hypothesized through the "personality-stress-health" model devised by Kinder (2005). Here, personality predicts positive health behaviour, coping strategies, and health while indirectly predicting "stressrelated disease". Notably, in the face of stress events, people tend to use different coping strategies depending on their personality traits, individuals with some traits may perceive less stress, which in turn may cause fewer psychological symptoms. For instance, certain Big Five traits appear to act as buffers against stress. One study noted that individuals with higher levels of responsibility experience less academic and social pressure (Murphy, Miller, \& Wrosch, 2013). Furthermore, neuroticism and introversion appear to be associated with chronic stress (Kondratyuk \& Morosanova, 2014), while gratitude, hope, and integrity are positive resources that buffer against stress (Duan, Ho, Siu, Li, \& Zhang, 2015). Additionally, Lu (2008) showed that hardiness moderates the relationship between stress and psychological symptoms. Hardiness is a kind of personality trait, which also belongs to positive personality resources.

One of the positive personality traits receiving particular focus among studies on adolescents is character strengths. Character strengths are regarded as healthy or positive personality traits and have an important role in determining teenagers' psychological health when experiencing psychological stress. Seligman and Peterson (2004) regarded character strengths as specific psychological content related to virtue. Carr (2013) indicated that character strengths are personality traits related to a better quality of life. Furthermore, character strengths are a set of positive traits reflected by an individual's thoughts, emotions, and behaviours (Snyder \& Lopez, 2002). These traits can be broken down into 10 standards: aids individuals in gaining satisfaction and happiness; moral significance; most people are able to follow through; the opposite of weakness; depends on the situation; uniqueness and integrity; widespread across cultures; some strengths will emerge early in children; and not everyone will clearly show all strengths; based on the corresponding sociocultural system. Seligman and Peterson (2004) ultimately outlined 24 character strengths, measured with the Values in Action Inventory of Strengths (VIA-IS). There are currently 5 versions of this assessment tool. Otake et al. (2005) developed a Japanese version of the VIA-IS; Brdar and Kashdan (2010) developed a Croatian version; and Duan et al. (2012) developed a Chinese version. These scales probe the concrete structure of strengths, and thus guide teenagers' positive growth. Several studies have found that certain character strengths are negatively correlated with psychological symptoms (Duan et al., 2015), as well as various psychological problems among teenagers, including depression, juvenile crime and violence, risky sexual activity, and drug abuse (Peterson, Park, \& Seligman, 2006). Furthermore, character strengths have significant positive correlations with academic success, prosocial behaviours, and a better quality of life (Park, 2004).

Therefore, it seems necessary to explore how to use and cultivate personality traits that buffer against the 
negative impact of stressful events and improve individual health. However, there is currently little research on this topic, especially for secondary vocational school students. The present study explored the personality-stress relationship from the perspective of advantages and potential. Namely, we examined the characteristics and relationships between secondary vocational school students' character strengths, psychological stress, and psychological symptoms in order to understand the factors influencing this sample's psychological health. This could help with developing education programs for improving these students' health and well-being.

\section{Method}

\subsection{Participants and Procedures}

School, teacher, and student parental permission was granted, and students (across three vocational school grades) agreed to take part in this project during the spring semester of 2015 (April). Using a stratified random sampling method, 100 students were selected from nine vocational areas (i.e., art, animation games, building decoration, computer graphic design, arts and crafts, costume design and process, hairdressing and image design, e-commerce, and business assistant) within each grade; thus, a total of 300 students were invited to participate. Students were asked to complete a questionnaire. Informed consent was obtained before participants completed the questionnaires. Ethics approval was obtained from the school administration.

Finally, 282 valid questionnaire responses were received, including 112 males and 170 females. Their mean age was 16.61 years $(S D=0.81$, range 16 - 19). The majority $(54.60 \%, n=154)$ came from rural areas; the remaining $44.40 \%(n=128)$ came from urban areas. One hundred and thirty-two $(46.80 \%)$ came from singlechild families, likely due to the one-child policy of Mainland China.

\subsection{Measurements}

Chinese Virtues Questionnaire (CVQ). The Chinese Virtues Questionnaire (CVQ) is a Chinese scale that assesses 24 character strengths belonging to three virtues: relationships (32 items), vitality (40 items), and conscientiousness (24 items) (Duan et al., 2012). The CVQ comprises 96 items in total. Respondents were asked to rate the extent to which each item described them on a 5-point Likert scale ranging from 1 (very much unlike me) to 5 (very much like me). The mean scores across the three virtues were obtained by averaging the scores for each subscale. Higher scores reflect a higher degree of that particular virtue within an individual. The Cronbach's alpha coefficients for the total questionnaire and the relationship, vitality, and conscientiousness subscales were good (Cronbach's alpha $=0.96,0.93,0.92$, and 0.90 , respectively).

Life Stress Rating Scale for College Students (LSRS). The Life Stress Rating Scale for College Students (LSRS) is a 60-item Chinese scale for measuring self-appraisals of life stress severity in the following domains: studies, social life, family, and development (Xu, 2004). Participants were asked to rate the severity (from $0=$ no influence to $4=$ very serious) and duration (from $1=3$ months to $3=6$ months or more) of each item. The total score was used as an indicator of overall psychological stress; subscale scores can be calculated, as well. The events covered in the scale are believed to apply to secondary vocational school students. However, to ensure that the items accurately applied to this group, we changed item 1 from "entering college" to "go to high school" and item 3 from "failed college entrance examination" to "failed high school entrance examination". In the current sample, the Cronbach's alpha for the total scale was 0.96, and the test-retest reliability correlation was 0.90 .

Symptom Checklist-90 (SCL-90). The Symptom Checklist-90 is a 90-item self-report scale assessing various psychological symptoms (i.e., depression, hostility, anxiety, phobic-anxiety, obsessive-compulsiveness, interpersonal sensitivity, somatization, paranoid ideation, and psychoticism; Derogatis, Lipman, \& Covi, 1973). Subjects are asked to rate each symptom on a 5-point Likert scale, ranging from 1 (absolutely not) to 5 (very much), according to the extent to which they experienced that symptom in the past 7 days. Higher scores indicated more frequent symptoms. The total score is the sum of the item scores, while the factor score is the mean of all items. The Cronbach's alpha coefficient for the total scale was good in the present study (0.97; Duan et al., 2015).

\subsection{Data Analysis}

Data analyses were conducted using SPSS 19.0. Descriptive statistics were used to describe the status quo and 
characteristics of the sample's character strengths, psychological stress, and psychological symptoms. $t$-tests were carried out to test differences on demographic variables such as gender, location, and family type; correlation analyses were used to assess the relationships between these variables. A hierarchical regression analysis was then conducted, in which we tested whether character strengths (relationship, vitality, conscientiousness) moderated the relationship between stress (study, social, family, development) and psychological symptoms.

\section{Results}

\subsection{Descriptive Statistics and $t$-tests}

The means and standard deviations of the three character strengths, psychological stress, and psychological symptoms are shown in Table 1. A $t$-test showed significant differences in relationship scores by gender $(t=$ 2.22, $p<0.05$ ), location (urban vs. rural) $(t=3.33, p<0.01)$ and family type (single-child family vs. non-single child family) $(t=3.72, p<0.001)$. Furthermore, there were significant differences in study stress scores by location $(t=-2.13, p<0.05)$ and family type $(t=-2.09, p<0.05)$, development stress scores by gender $(t=2.81, p$ $<0.01)$, and in psychological stress by location $(t=-2.63, p<0.001)$.

Correlations and Regression:

Correlations between character strengths, psychological stress, and psychological symptoms are shown in Table 2. The three virtues were all negatively and significantly related to psychological symptoms $(r=-0.42$ to -0.38 ) and psychological stress $(r=-0.17$ to -0.14$)$, while psychological stress was positively and significantly related to psychological symptoms. Notably, the relationship score on the CVQ was negatively and significantly related to the study, family, and development stress scores on the LSRS. Furthermore, the vitality score was negatively and significantly related to the study and family stress scores. The conscientiousness score was negatively and significantly related to the study and developmental stress scores. Social stress and the three strengths were not related and will no longer be discussed in the following analyses.

Multiple regression analyses were performed to independently examine the relative effects of the three character strengths on psychological stress and psychological symptoms. The three character strengths were set as the predictors, and psychological stress and symptoms as dependent variables in each regression equation. The results indicated that relationship subscale scores significantly predicted study, family, and developmental stress and psychological symptom scores as seen in Table 3; the vitality subscale scores significantly predicted study and family stress and psychological symptom scores; and conscientiousness significantly predicted study and developmental stress and psychological symptoms scores.

\subsection{Test of Moderation}

A hierarchical regression analysis was conducted to examine whether character strengths moderated the relationship between psychological stress and psychological symptoms. The dependent variable was psychological

Table 1. Descriptive statistics of main variables and comparisons by gender, location, and family type $(\mathrm{N}=282)$.

\begin{tabular}{|c|c|c|c|c|c|}
\hline \multirow{2}{*}{ Measure } & \multirow{2}{*}{ M } & \multirow{2}{*}{ SD } & \multicolumn{3}{|c|}{$\mathrm{T}$} \\
\hline & & & Gender & Location & Family type \\
\hline Relationship & 16.16 & 1.72 & -1.50 & 1.63 & -0.22 \\
\hline Vitality & 14.37 & 2.16 & $2.22^{*}$ & $3.33^{* *}$ & $3.72^{* * *}$ \\
\hline Conscientiousness & 14.01 & 2.06 & 1.95 & 1.14 & 1.66 \\
\hline Study stress & 8.46 & 6.13 & -0.04 & $-2.13^{*}$ & $-2.09^{*}$ \\
\hline Social stress & 11.85 & 9.81 & 1.56 & -0.83 & -1.31 \\
\hline Family stress & 4.94 & 5.93 & 1.15 & -0.93 & -0.34 \\
\hline Development stress & 4.69 & 5.02 & $2.81^{* *}$ & 1.31 & 1.40 \\
\hline Psychological stress & 29.93 & 22.26 & 1.64 & -0.90 & -0.92 \\
\hline Psychological symptom & 1.55 & 0.42 & 1.63 & $-2.63^{* *}$ & -1.56 \\
\hline
\end{tabular}


Table 2. Correlation analysis of virtues, stress, and symptoms $(\mathrm{N}=282)$.

\begin{tabular}{|c|c|c|c|c|c|c|c|c|c|}
\hline Measure & 1 & 2 & 3 & 4 & 5 & 6 & 7 & 8 & 9 \\
\hline 1. Relationship & -- & & & & & & & & \\
\hline 2. Vitality & $0.65^{* *}$ & -- & & & & & & & \\
\hline 3. Conscientiousness & $0.71^{* *}$ & $0.71^{* *}$ & -- & & & & & & \\
\hline 4. Study stress & $-0.15^{*}$ & $-0.27^{* *}$ & $-0.20^{* *}$ & -- & & & & & \\
\hline 5. Social stress & -0.06 & -0.06 & -0.04 & $0.70^{* *}$ & -- & & & & \\
\hline 6. Family stress & $-0.12^{*}$ & $-0.16^{* *}$ & -0.09 & $0.59^{* *}$ & $0.62^{* *}$ & -- & & & \\
\hline 7. Development stress & $-0.17^{* *}$ & -0.12 & $-0.20^{* *}$ & $0.44^{* *}$ & $0.51^{* *}$ & $0.46^{* *}$ & -- & & \\
\hline 8. Psychological stress & $-0.14^{*}$ & $-0.17^{* *}$ & $-0.14^{*}$ & $0.84^{* *}$ & $0.91^{* *}$ & $0.80^{* *}$ & $0.69^{* *}$ & -- & \\
\hline 9. Psychological symptom & $-0.38^{* *}$ & $-0.38^{* *}$ & $-0.42^{* *}$ & $0.44^{* *}$ & $0.42^{* * *}$ & $0.32^{* *}$ & $0.50^{*}$ & $0.51^{* *}$ & -- \\
\hline
\end{tabular}

Table 3. Regression analysis on psychological stress and psychological symptoms $(\mathrm{N}=282)$.

\begin{tabular}{cccc}
\hline \multirow{2}{*}{ Dependent variable } & & Independent variable (standard $\beta)$ & \\
\cline { 2 - 4 } & Relationship & Vitality & Conscientiousness \\
\hline Study stress & $-0.15^{*}$ & $-0.27^{* * *}$ & $-0.20^{* *}$ \\
Family stress & $-0.12^{*}$ & $-0.16^{* * *}$ & -0.09 \\
Development stress & $-0.16^{* *}$ & -0.12 & $-0.20^{* *}$ \\
Psychological symptom & $-0.38^{* * *}$ & $-0.38^{* * *}$ & $-0.42^{* *}$ \\
\hline${ }^{*} p<0.05,{ }^{* *} p<0.01,{ }^{* * *} p<0.001$. & & &
\end{tabular}

symptoms, while the interaction variables were relationship $\times$ study stress, relationship $\times$ developmental stress, relationship $\times$ family stress, vitality $\times$ study stress, vitality $\times$ family stress, conscientiousness $\times$ study stress, and conscientiousness $\times$ developmental stress. The demographic variables, including gender, location, and family type were entered in step 1; study, family, and developmental stress were entered in step 2; relationship, vitality, and conscientiousness were entered in step 3; and the interaction terms were entered in step 4 . The results are shown in Table 4. Briefly, the interaction between relationship and family stress explained nearly $45 \%$ of the variance; thus, the moderator model was supported in this sample.

\section{Discussion}

\subsection{Characteristics of the Secondary Vocational School Students' Psychological Stress}

Social stress was the main source of perceived stress among secondary vocational school students. According to an analysis of their educational background and psychological development, such students are often considered disadvantaged and are mostly neglected in elementary education due to learning disabilities. Furthermore, they experience considerable discrimination from teachers, parents, and peer groups, as well as wider social prejudice associated with vocational education. This leads to these students receiving a lack of support, which in turn can gradually lead to depression, a sense of inferiority, and social problems (e.g., social withdrawal and a greater unwillingness to communicate with others). When facing difficulties, in order to avoid acting "incompetent", "helpless", and limiting self-esteem, they are reluctant to adopt active social styles (Zhang \& Jiang, 2012).

Regarding study stress, it would seem that secondary vocational school students experience little study stress, at least compared to high school students. However, while they might find it easier to learn the requisite knowledge for their trade, they must also apply this knowledge in practice. Thus, their study stress mainly derives from difficulty in putting theoretical knowledge into practice, which is closely related to their future career development. Feeling unpowered, tiring of learning, and dropping can be serious consequences (Wu \& Yao, 2013). More than $40 \%$ of secondary vocational school students have all sorts of negative emotions associated with 
Table 4. Results of the hierarchical regression analysis $(\mathrm{N}=282)$.

\begin{tabular}{|c|c|c|c|c|c|}
\hline & Indicator & $\beta$ & $t$ & $\mathrm{R}^{2}$ & $\Delta \mathrm{R}^{2}$ \\
\hline \multirow[t]{4}{*}{ Step 1} & & & & 0.18 & 0.03 \\
\hline & Gender & -0.09 & -1.48 & & \\
\hline & Location & 0.12 & 1.79 & & \\
\hline & Family type & 0.05 & 0.72 & & \\
\hline \multirow[t]{4}{*}{ Step 2} & & & & 0.58 & 0.33 \\
\hline & Study stress & 0.25 & $3.81^{* * *}$ & & \\
\hline & Family stress & -0.01 & -0.16 & & \\
\hline & Development stress & 0.41 & $7.01^{* * *}$ & & \\
\hline \multirow[t]{4}{*}{ Step 3} & & & & 0.66 & 0.43 \\
\hline & Relationship & -0.12 & -1.66 & & \\
\hline & Vitality & -0.06 & -0.80 & & \\
\hline & Conscientiousness & -0.17 & $-2.25^{*}$ & & \\
\hline \multirow[t]{8}{*}{ Step 4} & & & & 0.67 & 0.45 \\
\hline & Relationship $\times$ study stress & -0.14 & -1.80 & & \\
\hline & Relationship $\times$ family stress & 0.19 & $2.89^{* *}$ & & \\
\hline & Relationship $\times$ development stress & -0.08 & -1.12 & & \\
\hline & Vitality $\times$ study stress & 0.03 & 0.39 & & \\
\hline & Vitality $\times$ family stress & -0.05 & -0.78 & & \\
\hline & Conscientiousness $\times$ study stress & 0.06 & 0.61 & & \\
\hline & Conscientiousness $\times$ development stress & -0.02 & -0.19 & & \\
\hline
\end{tabular}

${ }^{*} p<0.05,{ }^{* *} p<0.01, \stackrel{* * *}{p}<0.001$.

academics, including depression, anxiety, anger, shame, helplessness, and study fatigue (Zhao, 2014). Even more complex, individual achievement goals, self-awareness, and environmental conditions are the main factors underlying study stress emotions (Xu \& Gong, 2009).

Notably, study stress significantly differed by location and family type. This is perhaps because social resources and interpersonal relationship networks are important factors when a student is planning for his or her future. However, for students from rural areas, it is difficult to, on their own, leave the area in which they are born. As such, they are perhaps more likely to cherish the opportunities they have to learn, which can also become their primary motivation (and, thus, feel greater stress as a result). Regarding family type, students from one-child families are less likely to have higher study stress because their parents are not going to compare them to their siblings, and one-child parents can provide a rich variety of intellectual investment. Even if busy with work, parents can also arrange time with their child, cultivate their various artistic interests, and go to cultural events/institutions. This can broaden children's knowledge, make thinking more active, and promote learning beyond an academic context (http://www.baike.com/wiki/独生子女).

Regarding family stress, such as parents being laid off, economic difficulties, relatives passing away, and family disharmony, we noted no evidence that the frequency of family-related stressful events was greater among secondary vocational school students than among high school students. This is despite the fact that studies have noted that parental investment is lower among the former group than among the latter (Wu \& Yao, 2013). We conjecture that the influence of family stress on secondary vocational school students may be mediated by academic achievement and social ability, among other factors.

Developmental stress showed significant gender differences, with men being more concerned about their future development than women. From the perspective of the social division of labour and physical characteristics, males have traditionally had greater family economic responsibilities. Seginer (2009) points out that women put 
more of an emphasis on interpersonal relationships, while men experience more stress and anxiety in terms of vocational development.

The aforementioned findings regarding stress largely coincide with those of previous studies. Secondary vocational school students have more stress towards studying, social interaction, and development. Furthermore, students from rural areas tend to have much more anxiety regarding their future development than do students from urban areas, and males have more worry about future planning (Zhao, 2014). Secondary vocational school students are an important adolescent sub-group. Psychological stress related to their studies, social networks, family, and development needs to be acknowledged by teachers, parents, and society. Such attention should specifically focus on strengthening educational guidance and these students' family upbringing.

\subsection{Moderating Effects of Character Strengths}

Peterson and Seligman (2004) created a model of six virtues and 24 character strengths, which provides a new and positive perspective for helping people (especially teenagers) by viewing their potential advantages. However, their model has biases, particularly regarding the classification of character strengths, and this bias is likely in part caused by cultural differences (Linkins, Niemiec, Gillham, \& Mayerson, 2014). Thus, some researchers have revised this, and the present study used the Chinese version.

Compared with other sources of psychological stress, study and social stress had stronger influences on psychological symptoms in the present study. Both sources of stress relate to their future development, as the former relates to professional knowledge learning, while the latter reflects interpersonal communication. Secondary vocational school students' unique learning experiences, social expectations, future planning, and stage of mental development determine their various personality traits and strengths, which will likely differ from those of high school students. Furthermore, their attitudes towards the future development should also be different. We noted that the relationship strengths affected the degree to which secondary vocational school students' family stress predicted their psychological symptoms. As such, certain character strengths are important for determining the degree of psychological stress. This is similar to results from previous studies (Duan et al., 2015; Li, 2013).

The moderating effect of relationship strengths on the relationship between family stress and psychological symptoms suggests that individuals' cognitive evaluation of their social resources influences their ability to cope with stress and their subsequent mental health. Duan (2012) defines relationship strengths as a set of advantageous behaviours related to interpersonal performance that are similar to the social advantages proposed by Shryack et al. (2010). Maslow (1954) and Rogers (1951) both pointed out the importance of complete "respect and understanding” for individuals' freedom of expression and thoughts in repairing individuals' damaged potential for self-realization. The "people-first theory" advocated that "student-centred" teachers and parents can be potential sources of support for students by respecting students' independence and initiative. The moderating effect of the relationship strengths in the present study reflects the important influence of family upbringing on young students' psychological development. Family factors, such as the degree of family harmony, whether adolescents have been abandoned by a parent(s), and whether parents engage in destructive or dangerous behaviours, can lead to economic and psychological insecurity, social withdrawal, violent impulses, and other adverse psychological problems and behaviours. However, with sufficient relationship strengths, students can better resolve family problems, utilize family resources, integrate their own identity into their family, utilize their potential for pursuing self-fulfilment, inspect their own behavioural motives, be more responsible, and better integrate themselves into society. On the other hand, family factors, especially support from the nuclear family, are positively related to happiness, health, and adaptation (Dickerson \& Zoccola, 2009). Support from the family promotes happiness and health; this is because the relationship is able to meet one's affinity and belonging needs, relieves stress situation caused by negative emotions, and helps a person confidently confront challengers. Family dysfunction, confusion, and conflict can lead to more mental health problems for adolescents; family functioning and positive personality significantly predicts adolescent mental health (Lei, Suo, \& Li, 2011). Results from the present study provide support for the buffering role of strengths against stress and psychological problems among adolescents, especially among secondary vocational school students. How to integrate these findings with practical education is important. Relatedly, Seligman et al. (2005) designed and developed the "identify and use strengths" intervention. He et al. (2014) listed a series of activities using relationship strengths for interpersonal communication with friends, classmates, and the family, which included positive daily behaviours, 
hugging the person you love, understand others' behaviours, sincere compliments, and others. Furthermore, these studies provide implications for suitable individual development.

\subsection{Implications for Education and Family Upbringing}

When discussing the relationship between character strengths and healthy growth, scholars agree that character strengths are a reflection of the family's and school's environmental characteristics; if these characteristics are positive, they can enhance students' ability to resist psychological stress. However, future studies should adopt a multidimensional perspective to probe the concrete structure and developmental process of secondary vocational school students' character strengths for promoting positive growth. For secondary vocational school students, learning disabilities can lead to disharmonious parent-child relationships. The family is a microsystem that arguably has the strongest influence on individuals. For instance, individuals learn how to regulate their behaviour according to what their home environment is like. In particular, how parents interact with individuals is one of the most important factors affecting individual personality development (He et al., 2014). Recent research has investigated the prediction of parenting style and character strengths on students' psychological harmony (Duan et al, 2012). Additionally, adolescents' character strengths play different roles in predicting their future life satisfaction. For example, adolescents with strengths, such as kindness and cooperation, show fewer depressive symptoms later in life, while strengths such as love and spirituality predict greater future life satisfaction (Gillham et al., 2011). For secondary vocational school students, we might take a more targeted strategy towards identifying and developing their strengths and design effective interventions for improving the family environment and general education. Studies have noted that employment guidance, psychological counselling, training activities, role playing, etc. at school education (Hutchinson, Stuart, \& Pretorius, 2011), as well as frequent contact with the family and formulating collective family activity plans (He et al., 2014) may achieve these purposes.

Seligman, Steen, Park, and Peterson (2005) developed an intervention strategy called "identify and use strengths”. Currently, this is considered the best way to improve adolescents' positive psychological resources. This strategy includes various continuous training activities such as the "gratitude visit", "listing three good things every day", "immersion experience", and "identifying and using their strengths daily". Linkins et al. (2014) proposed using an education environment intervention framework based on five strengths to promote students' psychological resources, including teaching students a strength language and perspectives (i.e., an incentive language and vocabulary that can bring about positive emotions, confidence, and strength), helping them understand their own character strengths, practicing and applying those strengths, and identifying and developing the advantages of school and community organizations. Chinese researchers have modified and implemented an intervention plan to cultivate students' character strengths, thereby obtaining healthier minds and lives (via school and family education) and letting students discover and use their own advantages (Duan, 2012). Additionally, there is research from the perspective of mental resilience and self-esteem on how to help secondary vocational school students discover and improve their positive psychological resources (Zhang \& Jiang, 2012).

Although there are several interventions for promoting high school and college students' active development and healthy growth, there is a lack of similar interventions adopting a strengths perspective for secondary vocational school students. Future research should focus on the psychological and physiological mechanisms (and strength functions) among these students and identify how these students can discover and cultivate relationship, vitality, and conscientiousness strengths through intervention training. To ensure that teachers, parents, and society no longer view secondary vocational school students as disadvantaged, we must find ways for helping these children identify their own strengths.

\section{Acknowledgements}

This work was supported by The joint school's 2015-2016 education, social sciences, and medical research paper award program (JX2015009) We thank the funding support, editor, and anonymous reviewers for their useful comments and suggestions.

\section{References}

Brdar, I., \& Kashdan, T. B. (2010). Character Strengths and Well-Being in Croatia: An Empirical Investigation of Structure and Correlates. Journal of Research in Personality, 44, 151-154. http://dx.doi.org/10.1016/j.jrp.2009.12.001 
Carr, A. (2013). Positive Psychology: The Science of Happiness and Human Strengths. Beijing: China Light Industry Press.

Derogatis, L. R., Lipman, R. S., \& Covi, L. (1973). SCL-90: An Outpatient Psychiatric Rating Scale-Preliminary Report. Psychopharmacology Bulletin, 9, 13-28.

Dickerson, S., \& Zoccola, P. (2009). Towards a Biology of Social Support. In S. Lopez, \& C. R. Snyder (Eds.), Oxford Handbook of Positive Psychology (2nd ed., pp. 519-526). New York: Oxford University Press. http://dx.doi.org/10.1093/oxfordhb/9780195187243.013.0049

Duan, W. (2012). Boosting Well-Being: A Longitudinal Intervention Experiment Based on Character Strengths. Unpublished Master's Thesis, Chongqing: Southwest University.

Duan, W., Ho, S. M. Y., Siu, B. P. Y., Li, T., \& Zhang, Y. (2015). Role of Virtues and Perceived Life Stress in Affecting Psychological Symptoms among Chinese College Students. Journal of American College Health, 63, 32-39. http://dx.doi.org/10.1080/07448481.2014.963109

Duan, W., Ho, S. M. Y., Yu, B., Tang, X., Zhang, Y., Li, T., \& Yuen, T. (2012). Factor Structure of the Chinese Virtues Questionnaire. Research on Social Work Practice, 22, 680-688. http://dx.doi.org/10.1177/1049731512450074

Gillham, J., Adams-Deutch, Z., Werner, J., Reivich, K., Coulter-Heindl, V., Linkins, M., Winder, B., Peterson, C., Park, N., Abenavoli, R., Contero, A., \& Seligman, M. E. P. (2011). Character Strengths Predict Subjective Well-Being during Adolescence. Journal of Positive Psychology, 6, 31-44. http://dx.doi.org/10.1080/17439760.2010.536773

He, M., Yuan, Y., \& Duan, W. (2014). Found Our Resilience-The Application and Skill of Positive Psychology. Beijing: Social Sciences Academic Press.

Hutchinson, A. M. K., Stuart, A. D., \& Pretorius, H. G. (2011). The Relationships between Temperament, Character Strengths, and Resilience. In I. Brdar (Ed.), The Human Pursuit of Well-Being: A Cultural Approach (pp. 133-144). New York: Springer Science+ Business Media B.V.

Kondratyuk, N., \& Morosanova, V. (2014). The Relationship between Self-Regulation, Personality Traits and Job Stress Abstracts. Personality and Individual Differences, 60, S48-S78. http://dx.doi.org/10.1016/j.paid.2013.07.335

Lei, R., Suo, Y., \& Li, C. (2011). Relationship between Mental Health and Family Function, Teacher-Student Relations and Five-Factor Personality of Adolescents. Journal of Clinical Psychology, 19, 687-689.

Li, T. (2013). Study on the Relationship of Undergraduates' Character Strengths, Stress, and Mental Health. Unpublished Master's Thesis, Chongqing: Southwest University.

Linkins, M., Niemiec, R. M., Gillham, J., \& Mayerson, D. (2014). Through the Lens of Strength: A Framework for Educating the Heart. Journal of Positive Psychology, 10, 64-68. http://dx.doi.org/10.1080/17439760.2014.888581

Maslow, A. H. (1954). Motivation and Personality. New York: Harper.

Meng, W. (2008). The Theory of Positive Mental Health Education. Education Research, 29, 41-45.

Murphy, M. L., Miller, G. E., \& Wrosch, C. (2013). Conscientiousness and Stress Exposure and Reactivity: A Prospective Study of Adolescent Females. Journal of Behavioral Medicine, 36, 153-164. http://dx.doi.org/10.1007/s10865-012-9408-2

Otake, K., Shimai, S., Ikemi, A. et al. (2005). Development of the Japanese Version of the Value in Action Inventory of Strengths (VIA-IS). The Japanese Journal of Psychology, 76, 461-467. http://dx.doi.org/10.4992/jjpsy.76.461

Park, N. (2004). Character Strengths and Positive Youth Development. Annals of the American Academy of Political and Social Science, 591, 40-54. http://dx.doi.org/10.1177/0002716203260079

Peterson, C., \& Seligman, M. E. P. (2004). Character Strengths and Virtues: A Handbook and Classification. Washington DC: American Psychological Association.

Peterson, C., Park, N., \& Seligman, M. E. P. (2006). Greater Strengths of Character and Recovery from Illness. Journal of Positive Psychology, 7, 17-26. http://dx.doi.org/10.1080/17439760500372739

Rogers, C. (1951). Client-Centered Therapy: Its Current Practice, Implications and Theory. London: Constable.

Seginer, R. (2009). Future Orientation: Developmental and Ecological Perspectives (pp. 1-258). New York: Springer.

Seligman, M. E. P., Steen, T. A., Park, N., \& Peterson, C. (2005). Positive Psychology Progress: Empirical Validation of Interventions. American Psychologist, 60, 410-421. http://dx.doi.org/10.1037/0003-066X.60.5.410

Shryack, J., Steger, M. F., Krueger, R. F., \& Kallie, C. S. (2010). The Structure of Virtue: An Empirical Investigation of the Dimensionality of the Virtues in Action Inventory of Strengths. Personality and Individual Differences, 48, 714-719. http://dx.doi.org/10.1016/j.paid.2010.01.007

Snyder, C. R., \& Lopez, S. J. (2002). Handbook of Positive Psychology. New York: Oxford University Press.

Toner, E., Haslam, N., Robinson, J., \& Williams, P. (2012). Character Strengths and Wellbeing in Adolescence: Structure and Correlates of the Values in Action Inventory of Strengths for Children. Personality and Individual Differences, 52, 637-642. http://dx.doi.org/10.1016/j.paid.2011.12.014 
Wu, N., \& Yao, H. (2013). Parental Involvement and Vocational School Students’ Academic Engagement: The Moderation Role of Parenting Style. Psychological Science, 36, 899-903.

Xu, G., \& Gong, S. (2009). Academic Emotions and Its Influencing Factors. Advances in Psychological Science, $17,92-97$.

Xu, M. (2004). Life Stress Rating Scale for College Students. Unpublished Master’s Thesis, Shanghai: Shanghai Normal University.

Zhang, H., \& Jiang, Z. (2012). On the Relationship between Secondary Vocational School Students' Self-Esteem, Coping Styles and Resilience. Chinese Journal of Special Education, No. 9, 77-82.

Zhao, J. (2014). On the Present Situation and Characteristics of Secondary Vocational School Students' Academic Emotions. Chinese Journal of Special Education, No. 10, 78-86. 